\title{
Dynamic simulation in the processing industries: case studies from Mobil experience $\dagger$
}

\author{
J. W. WOMACK $\ddagger$ \\ Keywords: dynamic simulation, petrochemical simulation, training simulators, \\ dynamic simulation languages. \\ This paper provides an overview of Mobil's recent use of dynamic simulation. It \\ provides examples of applications to capital projects, to operator training, and to \\ existing facilities. Techniques and methodology of dynamic simulation are con- \\ sidered. Desirable future developments for dynamic simulation software are dis- \\ cussed.
}

\section{Introduction}

This paper discusses some of Mobil's recent experience in the use of dynamic simulation, expecting that this might be broadly typical of current CPI practice. Emphasis is placed on the kinds of things which have been done, and some of their benefits, rather than on details of technique. Two small examples of the simulation of subsystems are discussed in some detail. An overview of a larger, more typical, study is also included. Desirable future developments for dynamic simulation software are discussed, and an outline of MRDC's PC_plus_DataBase model development system is presented.

\section{Background and summary of Mobil applications}

In the last few years dynamic simulation has increasingly been recognised as a viable tool for system analysis and design, and its use by Mobil has grown steadily. Applications, see Table 1, have fallen into three major categories, which are

(1) Support of major capital projects. Mostly in the form of high-fidelity models capable of answering many of the 'what if' questions which arise during the engineering design, construction, and commissioning phases of a project.

(2) Operator training simulators, which have been acquired for an increasing fraction of both new and existing facilities over the past ten years.

(3) The solution of operational problems, the evaluation of process changes, and de-bottlenecking studies in existing facilities.

Table 1 includes, as Mobil applications, a number of dynamic simulations done for us by contractors or system vendors in which MRDC involvement was limited to review and/or acceptance of the work. None of the training simulator programs

Received 20 September 1985.

+ Paper presented at the International Seminar on Modern Methods in Dynamic Simulation of Industrial Processes, Trondheim., Norway, 1985. (C) Copyright 1985 Mobil Research \& Development Corporation.

$\ddagger$ Mobil Research \& Development Corp., Princeton, New Jersey, U.S.A. 
(I) In support of capital projects

\begin{tabular}{cc} 
Project/Location & Subject of simulation \\
\hline $\begin{array}{l}\text { Arun field projects.... } \\
\text { Indonesia }\end{array}$ & $\begin{array}{l}\text { (1) Gas injection compressor system } \\
\text { (2) LNG facility sub-systems, } \\
\text { eg. propane refrigeration loop. }\end{array}$ \\
$\begin{array}{c}\text { North Sea E. \& P. facilities } \\
\text { (a) Statfjord A Platform }\end{array}$ & $\begin{array}{c}\text { Gas/oil separation; gas handling; } \\
\text { compressor systems \& injection wells } \\
\text { (b) Beryl A platform }\end{array}$ \\
Grassroot Petrochemical Plant & (1) Facility-wide steam system \\
& (2) Ethylene unit sub-systems \\
New Zealand Synfuels Plant & (3) Poly-ethylene unit sub-systems \\
& (1) Facility-wide steam system \\
\hline
\end{tabular}

(II) For development of training simulators

\begin{tabular}{|c|c|}
\hline Project/Location & Subject of simulation \\
\hline \multicolumn{2}{|l|}{ (Analog simulators) } \\
\hline \multicolumn{2}{|l|}{ Joliet refinery } \\
\hline $\begin{array}{l}\text { Wilhelmshaven Refinery } \\
\text { Other refineries }\end{array}$ & $\begin{array}{l}\text { Crude unit(s), gas plant columns, } \\
\text { Boiler, fired heater, compressor, etc. }\end{array}$ \\
\hline \multicolumn{2}{|l|}{ (Digital simulators) } \\
\hline Yanbu Petrochemicals & Ethylene unit/ethylene oxide plant \\
\hline New Zealand Synfuels & Steam system, MTG unit, Basic training \\
\hline \multicolumn{2}{|c|}{ (III) In support of operating facilities } \\
\hline Project/Location & Subject of simulation \\
\hline USA hydrocracker unit & Multi-bed reactor $\&$ its controls \\
\hline Refinery steam system & Effect of connecting HP headers together \\
\hline Offshore gas/oil & (1) Re-wheeling in gas compression systems \\
\hline Production platforms & (2) Sales gas \& gas injection in parallel \\
\hline & (3) Inter-platform transfer line studies \\
\hline
\end{tabular}

Table 1. Applications of dynamic simulation within Mobil.

were written by us, for example, although our inputs often influenced their development. Note that most of the capital project support work has been done in-house. However, in some cases when the prime contractor has the capability for dynamic simulation, MRDC's role has been to review the models during their development, and to assist in translating their results into action.

The major objective for most of the work in support of capital projects has been to verify/check the adequacy of the control systems which have been designed. If dynamic simulation experiments indicate control or operational difficulties, then the dynamic models are used to develop solutions to these problems. Such changes are expected to be made prior to startup; therefore simulation engineers must work closely with the design engineers, and must convince them of the validity of the models. Once this confidence has been established, it is our experience that the models are used to answer many other 'what if' questions, not all of which are limited to control system operations.

The earliest of these simulation studies were completed during the design of gas injection facilities for the Arun gas field and of the associated LNG plant in 1975/6, 
Pobanz et al. (1980). These models were concerned with large multi-stage centrifugal compressors driven by gas turbines; gas compositions were constant, and control questions were related to load/throughput changes, to compressor anti-surge control, and to system responses after component failures and trips.

Mobil has built several major crude-oil production platforms in the North Sea, and dynamic simulation studies were conducted during the design of these platforms, Womack \& Lynn (1978) \& Hancock (1982). In each case the scope of the dynamic model included the main crude oil/gas separators, the gas compression systems, the gas injection wells, and all controls associated with this equipment. Simulation results again focussed on throughput changes, compressor anti-surge controls, and system responses to failures (especially to trips of the compressor drivers). Since these simulations were complete well before startup, the anti-surge controls designed for the simulation were used for initłal operations. This work yielded significant benefits in the early elimination of some problems, and in identifying unexpected interactions amongst control sub-systems. The simulation engineers were used off-shore during the commissioning of the early platforms because of their detailed understanding of operations, acquired through development and use of the dynamic models.

Facility-wide steam system models were developed for the New Zealand Synfuels plant, Kirkpatrick (1985), and for another grass roots facility. In each case these models were required because a relatively small number of large steam turbines seemed likely to dominate the system's behaviour. So, the models were used to study control system responses to trip/load rejection situations as well as to more gradual normal load changes. These models included steam generation (fired boilers, waste heat generators), distribution headers and let-down stations, major and minor steam turbines (and their loads), and associated controls.

All of these applications are characterised by the need for quite large, high fidelity, models and by the long period over which the models were used. Most of these dynamic models required between 100 and 400 differential equations, and were developed and used (intermittently) over periods of 6 to 36 months. We have not been able to obtain detailed validation of the models after the plant starts-up. However the continuing use of dynamic models and the absence of instances in which simulation-tested controls have proved inadequate indicates that results are generally accurate.

Mobil has used analog-computer-based training simulators for operator training in the use of plant controls since the start-up of the Joliet and Wilhelmshaven refineries in the early 1970 's. These simulations used relatively low-fidelity dynamic models, still based on proper mass and energy balances, both because of limited computing capacity and because they were adequate for the training purpose on hand. By about 1980 new process facilities were being equipped with control systems using CRT-based operator display stations, and the cost of digital computers had fallen dramatically. Training simulators purchased since then have been digital-computer-based; these have the computing capability to support higher fidelity models ... however there is a strong relationship between model fidelity and cost. A plant-specific model having fidelity adequate for pre-start-up training (and for new hires) but not for the 'refresher training' of an experienced operator might be expected to cost less than $\$ 80,000 \ldots$ while higher fidelity models (which may deliver some of the benefits of a 'design quality' dynamic simulation) can cost several times that amount. Mobil has had some experience with all of these types, see Table 1. 
MRDC has done relatively little work in using dynamic simulation for the solution of control problems with operating plants. This is due both to the length of time needed to develop useful models and to a shortage of simulation engineers. Dynamic simulation studies contributed to the resolution of initial operating problems with hydrocracker units in the early 1970's, but fortunately other new units have not experienced such severe control problems after start-up.

A significant amount of dynamic simulation work has been done in connection with de-bottlenecking and process revision studies for operating facilities. For example, it was demonstrated to a refinery that addition of a long header to connect two independent HP steam systems would yield large benefits after a boiler outage. Studies for offshore production platforms have included the effect of compressor re-wheeling (can three parallel trains be re-wheeled one at a time ... with two trains always in operation ... or does crude oil production have to shut down while all three are re-wheeled?), the impact on platform operations of switching recompressed natural gas between a sales gas pipeline and the gas injection compressors, and the impact on the gas compression systems of operating with inter-platform two-phase transfer lines.

This category of work is seen as a major area of opportunity for the application of dynamic simulation, if (see below) better software tools can reduce the time needed to develop dynamic models.

\section{Dynamic simulation methodology}

\section{I Computers and software}

A wide variety of tools have been used in dynamic simulations done on Mobil's behalf. All simulation models developed in-house have used IBM mainframe computer systems, but our contractors and vendors have used a variety of other systems as well, see Table 2. It is not important which computer is used, so long as it has enough power to provide timely results and has adequate methods of displaying them.

\begin{tabular}{|c|c|}
\hline \multicolumn{2}{|c|}{ (I) Computer systems } \\
\hline EAI 690 hybrid computer & Arun field inj. compressor study \\
\hline Autodynamics analog computer & Training simulators: Joliet, etc. \\
\hline $\begin{array}{l}\text { IBM 7094, 370/158, 3033, } \\
3083,4361 \text { (OS/MVS/CMS) }\end{array}$ & $\begin{array}{l}\text { All simulation studies for which } \\
\text { computer work was done by MRDC }\end{array}$ \\
\hline $\begin{array}{l}\text { UNIVAC } 1108 \text {; SEL } 3200 \\
\text { PDP 11-23 and 44; SAGE IV }\end{array}$ & $\begin{array}{l}\text { Used by contractors and/or } \\
\text { system vendors. }\end{array}$ \\
\hline \multicolumn{2}{|c|}{ (II) Software } \\
\hline $\begin{array}{l}\text { FORTRAN } \\
\text { CSMP and CSMP III } \\
\text { ACSL } \\
\text { DAP (Bechtel) } \\
\text { GEPURS (CE Simcon) } \\
\text { AUDYSIM (Autodynamics) } \\
\text { PASCAL }\end{array}$ & $\begin{array}{l}\text { As 'low level' language to others. } \\
\text { Original CSSL packages; obsolete. } \\
\text { Used for new MRDC work, ACSL (1981) } \\
\text { In-house package, Carlson (1982) } \\
\text { In-house FORTRAN-based languages } \\
\text { for training simulator development }\end{array}$ \\
\hline
\end{tabular}

Table 2. Computers and software used for dynamic simulation within Mobil. 
While FORTRAN is the dominant language which has been used, its current use is mostly as a vehicle for support of some higher level language. CSMP (from IBM) was an early example of such a language, and it was used for our initial North Sea related work. However, CSMP is essentially obsolete since support and maintenance are no longer available. MRDC now uses ACSL for its in-house work; this is a mature and reliable general purpose simulation language having good 'hot-line' support and maintenance. Also, it is available on many different computers which tends to make models more 'portable'.

The DAP language, developed by Bechtel, is also FORTRAN-based and is somewhat more process oriented than ACSL; it has been used successfully for several Mobil simulation studies. The GEPURS language, developed by Lummus/ CE Simcon, is aimed at rapid development of training simulator quality models in an interactive and real-time environment. It is also FORTRAN based, and has been used in both petrochemical and refinery applications on our behalf.

Numerical integration methods have been covered in depth by other papers in this seminar. We can confirm that stiff problems arise in practice, and that ACSL (and even CSMP) contain algorithms designed for use with such problems. However, we find that the Euler method is used more often; its simplicity makes constraints easy to handle, and choice of a 'small enough' stepsize is not hard. We do not appear to encounter those pathological situations for which results using smaller stepsizes do not converge to a single result. Computer time savings which might result from the use of more sophisticated methods are balanced by engineering time costs needed to specify error criteria separately for every integrator.

\subsection{Modeling techniques}

The first step in a new dynamic simulation is always an initial definition of scope, which is usually achieved by development of a Simulation P \& I.D. ("what you see is what you get ') and a statement of the study objectives.

Model development then follows a divide-and-conquer strategy; the key idea is that the full model is built up by the interconnection of small models (modules) each of which represents one of the blocks/items from the Simulation P \& I.D. And, every component model/module is tested and proven on a stand-alone basis before inclusion in the complete model because this sharply reduces time spent in debugging. Table 3 lists two categories of modules currently available within MRDC for use in new simulation studies.

Although the re-use of existing modules gets things off to a fast start, it is our experience that every project has enough special requirements that several new modules are required. Also, we do not expect this situation to change in the near future. Development of new modules requires analysis which is based on the use of dynamic mass and energy balances, equipment mechanical and performance data (from vendors or from tests), plus thermodynamic data and reaction kinetics information (as needed). The equations used for any new module are strongly influenced by the assumptions made during its development. The general techniques used for the development of lumped parameter models have been widely discussed, see for example Franks (1967, 1972), Luyben (1973) or Campbell (1958).

The level of detail included in any dynamic simulation model should be determined by the objectives of the study, since this has a major impact on the assumptions which can be made, and on the complexity and cost of the final model. 
(I) Generalised models (packaged for immediate re-use)

\begin{tabular}{ll}
\hline Controllers/control relays & Analog, not sampled data \\
Measuring transmitters & Measuring lags and scaling \\
Control values (gas/liquid) & Include valve dynamics and 'choking' \\
Flow resistance/pressure drop & For piping or equipment items \\
Gas phase capacity vessel & For one component systems \\
Steam capacity node & Mixing of superheated streams \\
Multistage compressors & Centrifugal or reciprocating \\
Gas turbine & Two shaft type \\
Steam turbine & Extraction; condensing; or 'small' \\
Saturated steam generator &
\end{tabular}

(II) Specialised models (not packaged for immediate re-use) (expected to need modification before use)

\begin{tabular}{ll}
\hline Multicomponent gas capacity & Mixing of superheated streams \\
Multicomponent flash/capacity & Mixing when two phases present \\
Fixed bed reactor(s) & Kinetics always different!! \\
Heat exchanger(s) & $\begin{array}{c}\text { Counter-current with and w/o phase } \\
\text { changes. Many variations possible. }\end{array}$ \\
\hline
\end{tabular}

Table 3. Component models/modules fo dynamic simulation within Mobil

However, for capital project work using broad definitions of objectives, we have tended to make assumptions which require more rigour rather than less. This is based on the experience that fast answers will always be needed for 'what if ' questions which we had not anticipated ... a more rigorous model is more likely to be able to provide meaningful answers in a timely fashion.

\subsection{Organisation and project consideration}

The development of an accurate dynamic model is not (often) the objective of a simulation study. More commonly it is required that the model be used to assess the operability of a unit, the robustness of a proposed control scheme, or the safety of a system under far-from-design operating conditions following a major upset.

Thus, the way in which the simulation engineers communicate with their 'clients' is of major importance. Table 4 lists the typical stages in the life cycle of a

\begin{tabular}{|c|c|}
\hline Stage & Requires interaction with ... \\
\hline Problem definition & $\begin{array}{l}\text { Project management; process, control, } \\
\text { equipment and operations engineers }\end{array}$ \\
\hline Formulate eqns. and math. model & Process, control and equipment engineers \\
\hline Collect data & Process, control and equipment engineers \\
\hline Build and validate model & Process, control and equipment engineers \\
\hline $\begin{array}{l}\text { Report on plan and model defn.: } \\
\text { discuss with users. }\end{array}$ & $\begin{array}{l}\text { Project management; process, control, } \\
\text { equipment and operations engineers }\end{array}$ \\
\hline Execute planned experiments & Process, control and equipment engineers \\
\hline $\begin{array}{l}\text { Resolve problems which } \\
\text { have been identified }\end{array}$ & $\begin{array}{l}\text { Project management; process, control, } \\
\text { equipment and operations engineers }\end{array}$ \\
\hline $\begin{array}{l}\text { Additional work to resolve } \\
\text { 'what if' questions }\end{array}$ & $\begin{array}{l}\text { Process, control, equipment and } \\
\text { operations engineers. }\end{array}$ \\
\hline $\begin{array}{l}\text { Final report and } \\
\text { archive model }\end{array}$ & \\
\hline
\end{tabular}

Table 4. Phases of work for a typical dynamic simulation study 
simulation study, and suggests the kind of interaction which is needed/ideal. Working relationships with process and facilities engineers can often be established by involving them in data collection, model validation, and development of a list of 'preplanned upsets'. Analysis of the results of simulation experiments is usually begun by the simulation engineers, but discussion of the results and of the conclusions drawn from them must involve other engineering disciplines if design or construction changes are actually going to be made. Our experience is that a well accepted dynamic model provides an excellent tool for the evaluation of alternative solutions to any problems which its use uncovers. However, the simulation engineers do not often develop the most practical solutions; getting input from process engineers, operations staff, etc is essential.

The largest benefits are obtained from a dynamic simulation study when a 'team approach' combines the efforts of those with process knowledge, those with mathematics and modeling skills, and those with engineering management authority so that key findings of a simulation study are correct, so that they are seen to be correct, and so that they are implemented.

\section{Application examples}

This section provides some detail about two small dynamic simulation studies, and an overview of the use which has been made of a larger (more typical) dynamic simulation model.

\section{I. Start-up of a motor-driven gas injection compressor}

One of the North Sea production platforms for which we developed a dynamic model uses an electric motor driven centrifugal compressor for gas injection. In the platform model this was treated as a constant speed machine, and was easy to represent. However, its start-up had required special enginerring because the offshore electrical system was too small to withstand the sudden addition of an $8 \mathrm{MW}$ load. A small dynamic model was developed for the start-up of this motor to check the electrical load calculations and to help establish sizing criteria for some control valves.

(This is typical of the requests which develop during the analysis-of-results stage of a simulation project as other engineers realise the capability of dynamic models to give quantitative answers to questions previously resolved by 'engineering judgment'. It also points to the need for several models for each project rather than just one; except for its startup [a period of fifteen seconds] an electric motor can always be treated as a constant speed device!)

Figure 1 is the Simulation P \& I.D. used for this study. Note that it is our common practice to use the Simulation P \& I.D. to define the notation used in the simulation equations (as shown) and to include instrument tags, pipe and equipment numbers (not shown) so that this drawing can better serve as a means of communicating with process engineers, etc. The injection gas compressor is driven by a squirrel-cage induction motor. The gas supply node (1) will be at a pressure of about $2500 \mathrm{psi}$ at the time when the injection compressor is to be started. The startup strategy is to pressurise the compressor system at a lower than normal pressure, about $1250 \mathrm{psi}$, and to use only $70 \%$ of the design excitation voltage for startup, then to switch to full voltage after a few seconds. The anti-surge control valve, V02, 


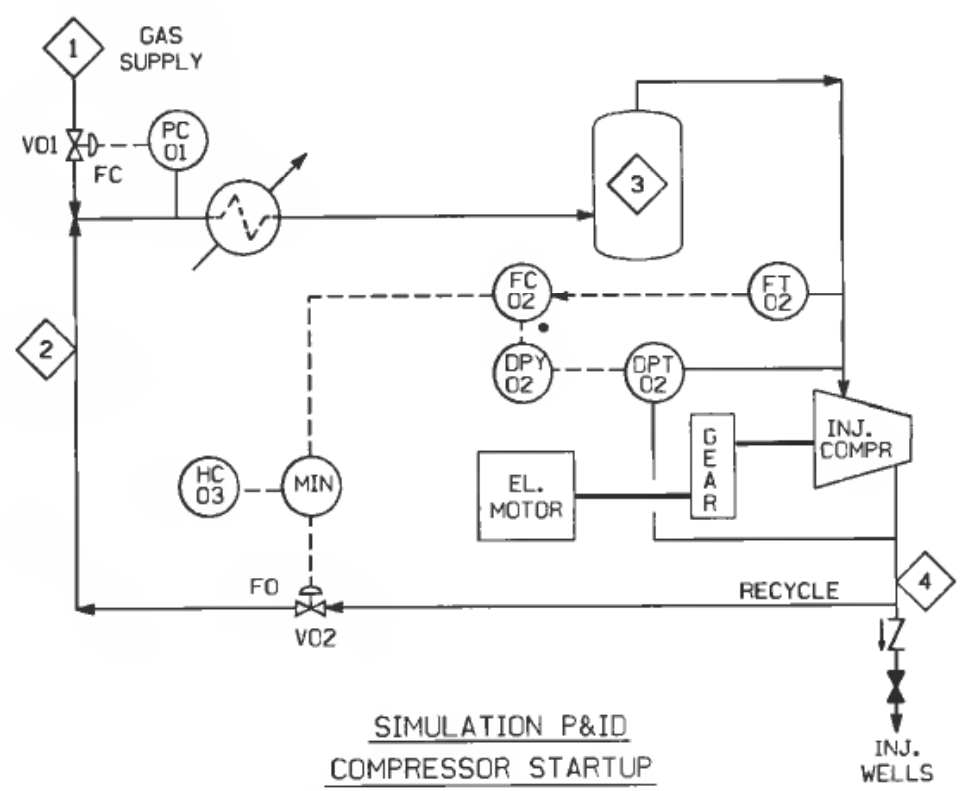

Figure 1. Simulation P \& ID compressor start-up.

is kept wide open under control of the start-up sequencer until the motor has reached full speed. There was concern that the starting torque/current might be too large; that the recycle control valve might be too small; and that the gas supply valve might be wrongly sized.

A conventional lumped parameter model is used to calculate the transient gas pressure and flow distribution. There are assumed to be only four different pressures in this system, the supply pressure (P1), the compressor suction and discharge pressures (P3 \& P4) and the pressure (P2) in the piping system upstream of the suction cooler. The volume of node \# 2 includes all of the piping plus half the volume of the heat exchanger tubes; it is assumed that all frictional pressure drop in the piping is much less than the pressure drop across control valves or the heat exchanger.

Since there is no change in gas composition, it is appropriate to use the standard one-component-gas-capacity macro based on a dynamic mass balance equation, viz:

$$
\frac{\mathrm{d} P}{\mathrm{~d} t}=\frac{\text { Z.R.T. }}{\text { Vol. } \mathrm{MW}} \cdot\left(W_{\mathrm{in}}-W_{\text {out }}\right)
$$

The standard (turbulent flow) resistance macro is based on eqn. (2) since flowrates are caused by pressure differences and the inertia of the flowing fluid is insignificant.

$$
W=K \sqrt{\left(\rho_{\text {in }} \cdot\left(P_{\text {in }}-P_{\text {out }}\right)\right)}
$$

Gas flow through control valves is calculated by another standard macro which includes valve travel dynamics and the ISA equations for calculation of flowrate. During the motor start-up only PC-01, the gas supply pressure loop, is active because $\mathrm{V} 02$ is held fully open by a sequence controller.

Flow through the compressor is calculated from the suction and discharge pressures, $\mathrm{P} 3$ and P4, and the compressor speed by first computing the polytropic head, $H p$, then using the fan laws and the design-speed performance curve to determine 
the suction volumetric flowrate, $Q$.

$$
\begin{aligned}
H_{\mathrm{p}} & =\frac{\text { Z.R.T. }}{\beta \cdot \mathrm{MW}} \cdot\left[\left(\frac{P_{4}}{P_{3}}\right)^{\beta}-1\right] \\
Q_{34} & =f_{1}\left(H_{p}, N\right) \\
W_{34} & =Q_{34} \cdot \rho_{3}
\end{aligned}
$$

The suction temperature is assumed to be held at the setpoint of the temperature control loop for the inlet cooler. While this is not an accurate assumption, it is a good one because temperature variations will be small (eqn. 3 uses absolute temperature) and meaningful temperature calculations would significantly increase the model complexity.

The compressor speed is calculated from a dynamic power balance, eqn. 6, where $K$ is the moment of inertia of the compressor-gear-motor system referred to the speed of the compressor.

$$
\text { K.N. } \frac{d N}{d t}=\alpha \cdot T_{M} \cdot N-B_{c}
$$

The power consumption of the compressor is

$$
B_{c}=\left(H_{p} \cdot W_{34}\right) / \eta
$$

And, the motor torque is obtained from the two curves in Fig. 2 as $T_{M}=f(N)$. Each of these curves is represented by an ACSL TABLE-function, and the model is able to switch from one to the other at the time selected for changing to $100 \%$ excitation voltage. Initial conditions for the speed equations, $5 \& 6$, were taken as Time $=0.2 \mathrm{sec}$ and Speed $=1.0 \%$ (calculated on basis of constant acceleration caused by zero-speed torque) in order to avoid a divide-by-zero problem if $N=0$.

Most of the source code for the DERIVATIVE region of this ACSL model is listed in Table 5. Key results from Time $=0$ to 25 secs for one run of the model are shown in Figs. 3 \& 4. Figure 3 shows that the motor continues to accelerate at

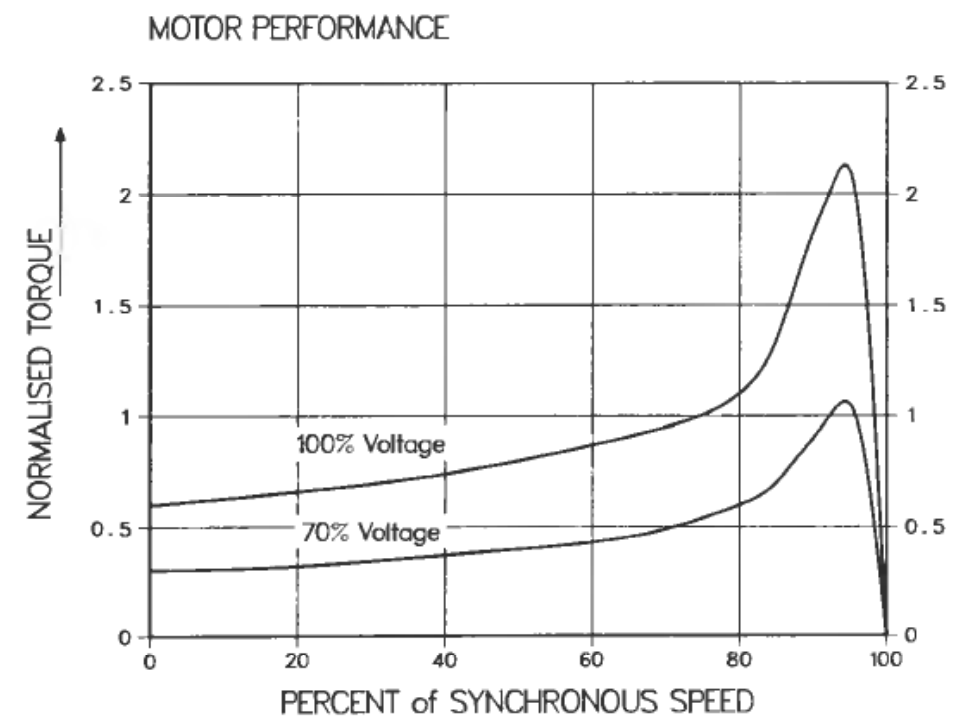

Figure 2. Motor performance. 
DERIVATIVE $\$$ COMPUTE ODE-DERIVATIVES HERE,

'MODEL ONLY INCLUDES ACTIVE CONTROL LOOPS'

PT01 $=$ TRANSD (P02, PT01HI, PT01LO)

CNT01 = CNTRL2 (PT01, SP01, GAIN01, RESET1, CNT01I)

W12, XV01 = GASVLV ( P01, P02, RHO01, CNT01, .. CV01, 'FC', TAUV1, LIMV1, XV01I)

RHO01 $=(\mathrm{P} 01 * \mathrm{MW}) /(10.73 * \mathrm{Z} * \mathrm{~T})$

'...P01 IS SUPPLIED AS A FORCING FUNCTION....'

$\mathrm{P} 02=$ CAPCTY $(\mathrm{W} 12+\mathrm{W} 42, \mathrm{~W} 23, \mathrm{~V} 2, \mathrm{~T}, \mathrm{MW}, \mathrm{Z}, \mathrm{P} 02 \mathrm{I})$

W23 $=$ RESIST ( P02, P03, RHO02, CF23 )

RHO02 $=($ P02*MW $) /(10.73 * Z * T)$

'...HEAT EXCHANGER THERMAL PERFORMANCE NOT MODELLED'

P03 = CAPCTY ( W23, W34, V3, T, MW Z, P03I)

'...COMPRESSOR MODEL USES PERFORMANCE DATA. ....'

W34, Q34, PLYH, EFF, BC, TOUT $=$ COMPR $($ P03, P04, . .

P04 = CAPCTY ( W34, W42, V4, TOUT, MW, Z, P04I)

$\mathrm{MW}, \mathrm{Z}, \mathrm{T}, \mathrm{K}$, SPEED)

W42, XV02 = GASVLV $($ P04, P02, RHO04, $\mathrm{HC} 03$,

RHO04 $=($ P04*MW $) /(10.73 *$ Z*TOUT $)$

CV02, 'FO', TAUV2, LIMV2, XV02I)

'. .POWER BALANCE COMPUTES COMPRESSOR SPEED...'

SPEED $=$ INTEG $($ (K1*TMOTOR-(K2*BC/SPEED))/MINERT, . . SPEEDI )

' .MINERT IS ROTATING STRING MOMENT OF INERTIA. .'

.....K1 \& K2 ARE DIMENSIONAL CONSTANTS. ....'

PROCEDURAL (TMOTOR = SPEED, TIME, TSWTCH)

IF (TIME.LT.TSWITCH) TMOTOR $=$ LOVOLT (SPEED)

IF (TIME.GE.TSWITCH) TMOTOR $=$ HIVOLT (SPEED)

' . . LOVOLT \& HIVOLT ARE ACSL TABLE FUNCTIONS. ..'

$\therefore$. REPRESENT FIGURE 2 PERFORMANCE CURVES. . . ...'?

END \$OF CALCULATION FOR MOTOR TORQUE'

END \$OF THE DERIVATIVE SECTION FOR ACSL PROGRAM'

TABLE 5. Start-up study for centrifugal compressor: ACSL code for derivative section

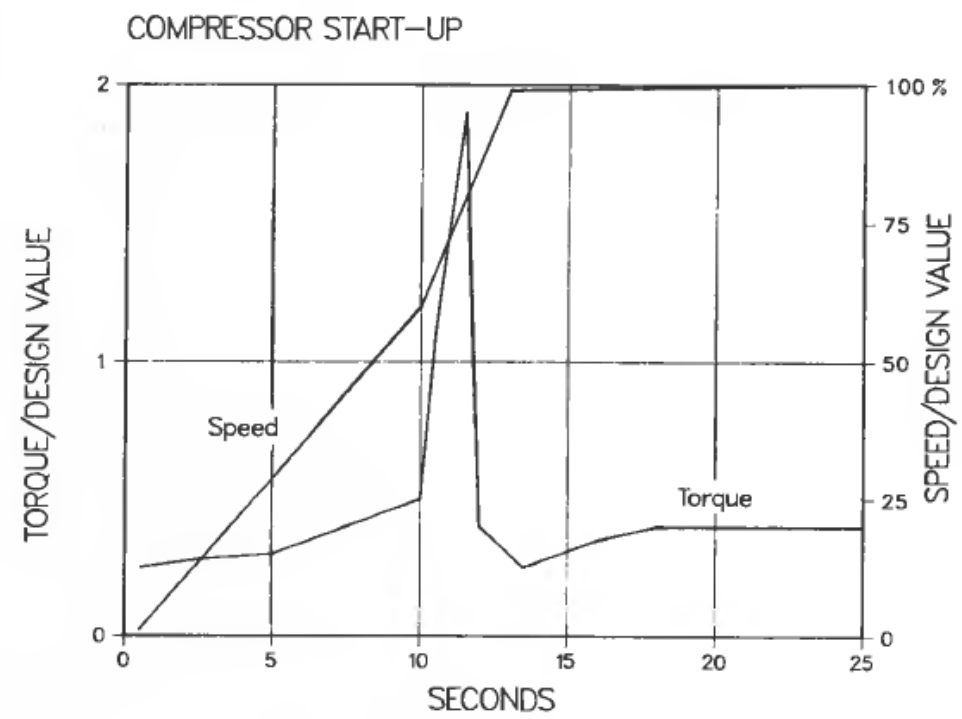

Figure 3. Compressor start-up. 
COMPRESSOR START-UP

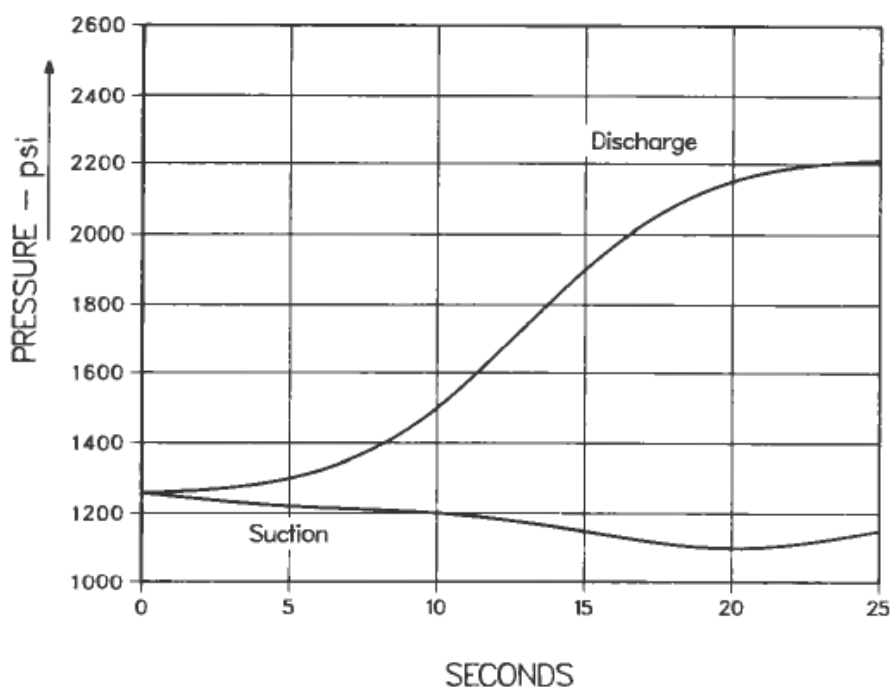

Figure 4. Compressor start-up.

roughly the initial rate throughout the 10 -sec low voltage period, since the compressor load (approximately proportional to $N$-cubed) is very low below $50 \%$ of full speed. The motor reaches design speed in about two seconds after the full exitation voltage is applied; during this time peaks occur in motor torque (and current). Figure 4 shows the pressure effects of the compressor 'moving inventory' to the high-pressure discharge capacity/node. After about $15 \mathrm{sec}$ the supply control valve, V01, opens partially for a few seconds ... and then closes again as pressure is restored to the setpoint.

Other simulation runs modelled the entire starting sequence; at about $90 \mathrm{secs}$ valve V01 is opened fully so that this system reaches its normal suction pressure over a one/two minute period; and then, at about 300 secs, HC-3 is ramped shut so that the compressor recycle flowrate is reduced to that required by the surge controller and the system is ready for gas injection.

During the design phase, parameter sensitivity runs with this model were used to confirm the motor start-up procedure and the initial setpoint for PC-01; to size V01; and to test the surge control loop settings. The model was then archived, and it was revived at short notice during commissioning of the equipment (two years later) and used to establish parameters for starting up the system with a gas having molecular weight sharply different from the design value.

\subsection{Fuel switch-over on an ethylene cracking furnace}

In normal operation most of the fuel for an ethylene cracking furnace is provided by the hydrogen-rich off-gas stream from the cold box; this has a molecular weight of about 5 . However, following a trip of the charge gas compressor, this fuel supply stops quickly. In a recently designed gas-fed ethylene plant, the raw feed gas is used as furnace fuel after such a trip; it has a molecular weight of about 30 . The fuel gas burners can handle this big MW change, but unless fuel gas pressure is reduced upstream of the burners there will be a dangerous shortage of combustion air in the firebox because the heavy fuel requires more air for complete combustion. 


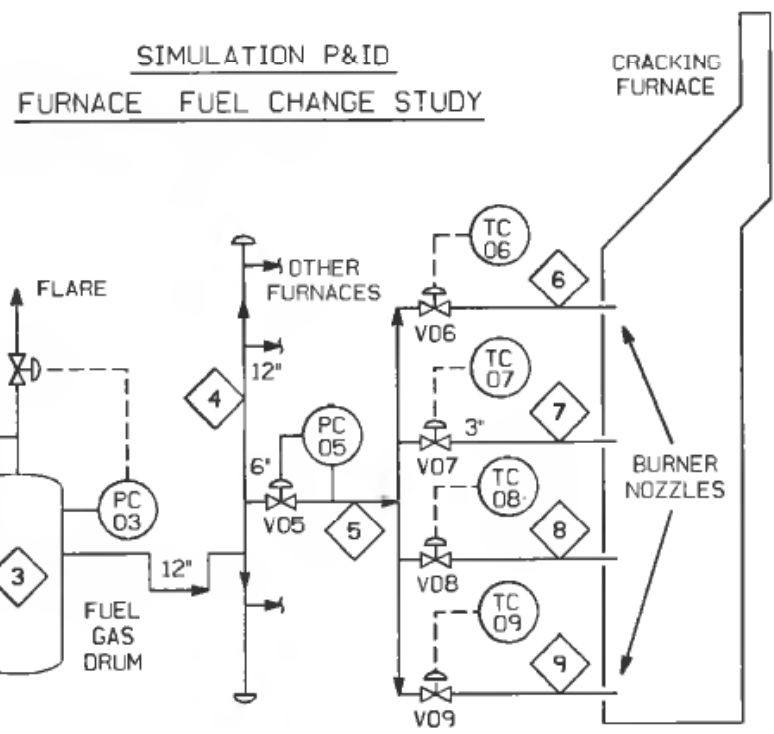

Figure 5. Simulation P \& ID furnace fuel change study.

The burner control system was designed to handle this situation, but because of the size of the fuel gas headers it was decided to check the control system performance by use of dynamic simulation.

Figure 5 is the simulation P \& I.D. This shows that all the available Off-gas flows into the Fuel Gas Drum. The drum pressure is usually controlled by PC02 which manipulates a 2 " control valve. Fuel gas flows through a long $12^{\prime \prime}$ supply pipe to a header which feeds several furnaces. There are four independent temperature control loops per furnace, each of which controls firing rate by varying the fuel gas pressure at the burner spud. If the Off-gas fuel supply is interrupted, PC02 opens V2 fully, but this $2^{\prime \prime}$ valve has been carefully sized so that it cannot supply enough gas to maintain PC02 at its setpoint. The fuel gas pressure falls until controller PC01, which has a lower pressure setpoint, opens the $4^{\prime \prime}$ fuel valve to balance supply and demand.

Process dynamic responses are described by a nine-capacity lumped parameter model, as indicated in Fig. 5. Pressure and composition of the fuel gas at each node are computed by six-component dynamic mass balances; fuel gas temperature effects are not important. The equations are ...

Mass balance per component $\quad \frac{d M_{i}}{d t}=\sum_{\mathrm{in}} W_{\mathrm{in}} \cdot X_{\mathrm{in}, i}-W_{\mathrm{out}} \cdot X_{i}$

Mass fractions from

$$
X_{i}=M_{i} / \sum_{i} M_{i}
$$

Node pressure from

$$
P=\frac{Z \cdot R \cdot T .}{\operatorname{Vol}} \cdot \sum_{i} \frac{M_{i}}{M W_{i}}
$$

Controllers and control valves use standard models. The gas burner model, based on performance data from the vendor, calculates the fuel flowrate from a power law function, ...

$$
W_{F}=f(P, M W, L H V)
$$


Combustion air required,

$$
W_{A}=\sum_{i} W_{F} \cdot X_{F i} \cdot A_{i}
$$

The low heating value, $L H V$, is calculated from handbook data, (given the fuel composition, $\mathrm{Xi}$ ) as are the $\mathrm{Ai}$ coefficients, for air required for complete combustion per pound of component $i$.

The above equations model the fuel gas system, and are able to compute the fuel flowrate, pressure, and composition changes which follow a compressor trip. Note that furnace temperatures are not modeled at all, since this would greatly complicate the model without altering its conclusions. The first model runs assumed that TC06, etc were in manual mode, so the TCV's do not move, while later runs assumed that the TCV's were driven open as fast as possible. It was further assumed that the air supply to the burners remains constant. Off-line calculations of furnace draft were then made, using the computed fuel flowrates to obtain temperature profiles; on this basis the constant combustion airflow assumption was validated.

Initial simulation results showed satisfactory control system responses, given a good choice for the setpoint and loop tuning constants of PC01. (Note that the model was used to establish these 'good choice' values.) The model was then used for a number of parameter sensitivity runs to test that performance remained good with fewer furnaces on-line, and in spite of different control loop tuning and control valve dynamic responses. Figure 6 shows one of these system responses; note that excess combustion air, the key variable, initially rises ... as the off-gas fuel flow decreases ... then overshoots to a minimum value before settling to a lower-thaninitial steady value. These results were judged to be acceptable after review by furnace and operations specialists. And, best of all, the control scheme has been shown to work properly in the plant; the compressor did trip, and the furnace remained on line with only a minor upset.

FURNACE FUEL SWITCH

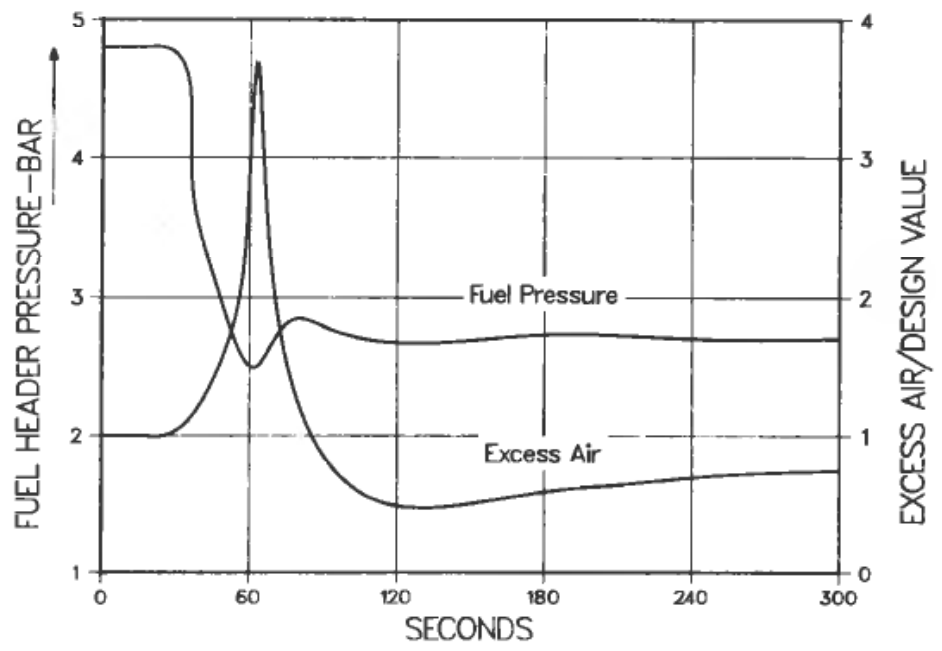

Figure 6. Furnace fuel switch. 


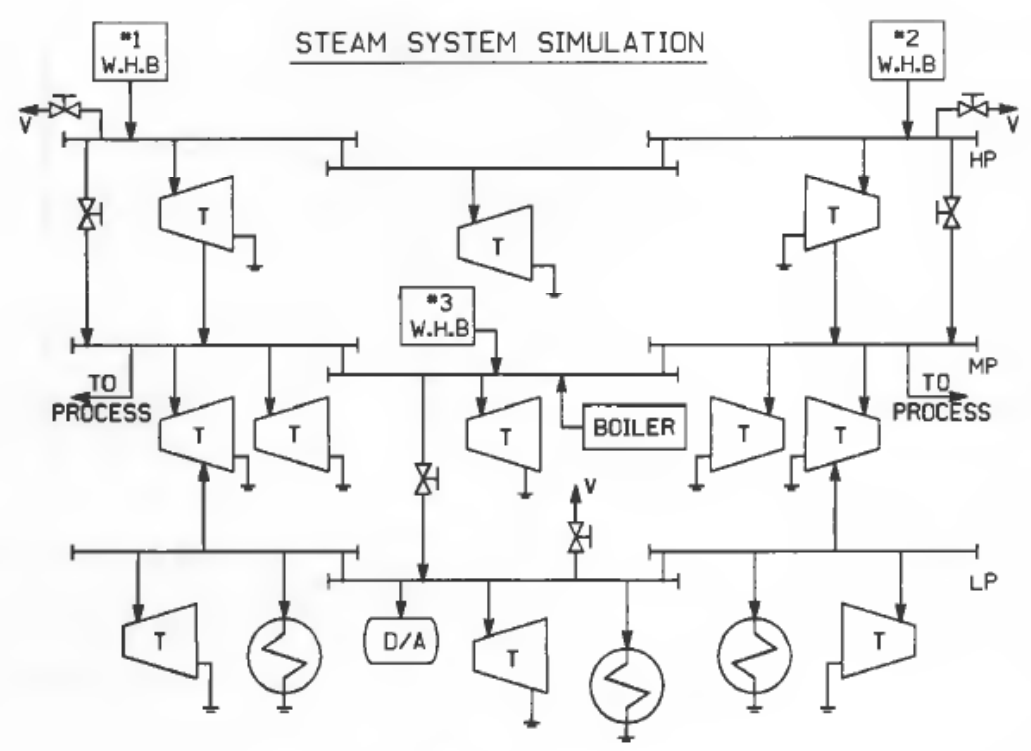

Figure 7. Steam system simulation.

\section{Facility-wide steam system study}

As an example of a more typical design phase dynamic simulation study, consider the work done on the steam system of the synthetic fuels facility now being built in New Zealand. Figure 7 is a very simplified sketch of this system; there are three steam headers, each at a different pressure; there are five major steam turbines (driving compressors) and about twelve smaller turbines; there are two HP steam generators (each having three steam drums) which are actually waste heat boilers in the exhaust ducts of the two methanol reformer furnaces. The control system model includes about forty loops, and the full dynamic model has somewhat over four hundred differential equations.

A dynamic model for this steam system was developed quite early in the design stage of the project. This was used to simulate the effect of a number of major trips and equipment failures, and was archived after those results had been fully discussed. Midway through the construction phase of the project the model was updated, as there had been many minor changes over a two-year period, and used to answer several new 'what if' questions. The results led to some significant changes in the control system; and to establishment of rational and practical load shedding strategies (for use after a trip of one steam generator). They were also used in the development of a special training simulator program for the steam system.

\section{Future developments}

At present a major weakness is that process dynamic simulation is expensive, and time consuming; thus its use tends to be restricted to major projects/problems.

Since the cost of raw computation continues to fall rapidly, it is obvious that we should look for better software to correct this weakness. There have been a number of attempts in this direction, but versatile and flexible Process Dynamic Simulation Packages are not currently available. 
Key features of such a package will include.... (i) a user-friendly interface so that the 'new user entry fee' is small enough that process or control engineers can play a significant part in future dynamic simulation studies. (ii) the availability of many simple models so that 'first cut' dynamic analysis can contribute to process feasibility studies. (iii) the ability to have 'expert users' extend the system by addition of other component models on a temporary or permanent basis. And, (iv) a data transfer interface to steady state process simulation packages so that stream specifications and physical property data can be used more quickly and reliably.

A successful package would let us exploit the $80 / 20$ rule; it could be expected to accomplish $80 \%$ of the work very quickly, freeing the simulation specialist to attend to the $20 \%$ which cannot be handled by the models contained in the Package.

MRDC has begun development of a package having some of these features, with the objective of making at least all of the generalised component models, see Table 3, easily available for use by non-specialists. We regard ACSL as an effective general purpose simulation language, and are grafting Process Simulation features onto it by providing a special user interface. The user must define the scope of his dynamic model by preparing a Simulation P \& I.D. and by collecting the data needed to define the physical system. He is then 'interviewed' by a custom-written dBASE III program, which runs on an IBM PC/AT, and which organises the data and system inter-connection information (from the P \& I.D.). When the interview process is finished the PC generates two files: a complete, ready to translate, ACSL program for the dynamic model of the Process Simulation P \& I.D., and a skeleton of the Run_Time_Data_File which is needed to execute experiments with the ACSL model. Thus, if the physical system can be modelled entirely with components included in the PC_Program_Generator, the user need know nothing about the syntax of ACSL. The PC_generated files are transferred to the mainframe computer for execution, although this may be done on the PC for small models.

It has been our experience that no dynamic simulation study has been completed without the development of some special component models. This difficulty will to be handled in two ways. First, the PC_Program_Generator software system can be modified to include additional component models, by means of another interview process with an 'expert user'. Alternatively, the simulation engineer can modify the PC_generated ACSL program before it is translated, adding code to represent the 'special features' of the physical system for which standardised models do not exist (or are not adequate).

\section{Conclusion}

The value of dynamic simulation is well established, as demonstrated by a continuing heavy workload. Benefits flow from better understanding of systems, from the reduction of unexpected control loop interactions, and from the 'quality control' aspect. We strive to reduce the Opinion Engineering content of plant design, and to provide 'twenty-twenty hindsight before start-up'.

The biggest factor limiting the use of dynamic simulation seems to be that it is too difficult! This makes it expensive, and a slow-to-use tool. Better software systems and faster/cheaper computers will help, and perhaps the use of parallelprocessor computers will cause a major change. However, experience suggests that today's target ought to be to provide general tools which can quickly solve $80 \%$ of the typical problem, and which permit the simulation engineer's expertise to add the 
last $20 \%$. Our work with the PC_Program_Generator system has this objective. Dynamic simulation seems likely to remain a specialist activity because of the uniquely broad range of its involvement across discipline lines in any major project.

\section{REFERENCES}

ACSL (1981). Advanced Continuous Simulation Language Users Guide/Reference Manual (Mitchell \& Gauthier, Assoc, Inc., Concord, Mass.)

Campbell, D. P. (1958). Process Dynamics (John Wiley, New York)

CARLSON, A. M. (1982). DAP-A Bechtel approach to dynamic simulation Proceedings, Summer Continuous Simulation Conference, Denver, Co.

FranKs, R. G. E. (1972). Modeling \& Simulation in Chemical Engineering (Wiley-Interscience, New York).

FranKs, R. G. E. (1967). Mathematical Modeling in Chemical Engineering (John Wiley, New York).

HancoCK, W. P. (1982). Development of a reliable gas re-injection operation for the Statfjord A platform. Presented at 57th. Annual Conf of the Society of Petroleum Engineers of AIME, New Orleans.

KIRKPATRICK, R. D. (1985). The NZSFC gas-to-gasoline plant. Presented at the Annual Meeting of the Institute of Professional Engineers in New Zealand, Wellington, NZ.

LuYbeN, W. L. (1973). Process Modeling, Simulation \& Control for Chemical Engineers (McGraw-Hill, New York).

Pobanz, N., MiYasakI, R. and WARREN, D. (1980). Applications of dynamic simulation to LNG plants. Proc. 9th Annual Convention of the Indonesian Petroleum Association, Jakarta.

WOMACK, J. W. and LyNN, L. L. (1978). 'Dynamic simulation of a gas injection facility'. Proceedings, Summer Continuous Simulation Conference, at Newport Beach, Ca. 